This is the author's manuscript for publication. The publisher-formatted version may be available through the publisher's web site or your institution's library.

\title{
The Impact of Premarital Cycling on Early Marriage
}

Amber Vennum and Matthew D. Johnson

\section{How to cite this manuscript}

If you make reference to this version of the manuscript, use the following information:

Vennum, A., \& Johnson, M. D. (2014). The impact of premarital cycling on early marriage.

\section{Published Version Information}

Citation: Vennum, A., \& Johnson, M. D. (2014). The impact of premarital cycling on early marriage. Family Relations, 63(4), 439-452.

Digital Object Identifier (DOI): 10.1111/fare.12082

Publisher's Link: http://onlinelibrary.wiley.com/doi/10.1111/fare.12082/pdf

This item was retrieved from the K-State Research Exchange (K-REx), the institutional repository of Kansas State University. K-REx is available at http://krex.ksu.edu 
Running head: PREMARITAL CYCLING AND EARLY MARRIAGE

The Impact of Premarital Cycling on Early Marriage

\author{
Amber Vennum, $\mathrm{PhD}$ \\ Kansas State University \\ Matthew D. Johnson, PhD \\ University of Alberta
}

Amber Vennum, Assistant Professor, School of Family Studies and Human Services, Kansas State University, 212 Campus Creek Complex, Manhattan, KS, 66506-1403, 785-5321489, avennum@ksu.edu.

Matthew D. Johnson, Assistant Professor, Department of Human Ecology, University of Alberta, 339 Human Ecology, Edmonton, AB, Canada T6G 2N1, 780-492-5008, matt.johnson@ualberta.ca 


\begin{abstract}
Using a sample of 564 newlywed couples and the enduring dynamics model of marriage (Caughlin, Huston, \& Houts, 2000), we examined the impact of premarital cycling (breaking up and renewing) on the entrance into marriage and relationship dynamics over the first five years. Consistent with the enduring dynamics model, results demonstrated cyclical couples (compared to non-cyclical couples) exhibited worse adjustment on a variety of relationship indicators at the entrance to marriage and were more likely to experience a trial separation over the first five years. Dyadic parallel process growth curve analysis further revealed that premarital cycling predicted lower initial relationship satisfaction that was sustained over the first five years of marriage. Implications for theory, research, and intervention with premarital couples are discussed. These results provide evidence that courtships characterized by breakups and renewals represent a relational vulnerability with negative implications extending years into the future.
\end{abstract}

Key words: courtship, enduring dynamics model, newlywed marriage, preventing marital distress, relationship cycling, marital satisfaction 
The Impact of Premarital Cycling on Early Marriage

Recent research suggests $30-50 \%$ of young adult dating partners and one-third of cohabiting couples experienced at least one breakup and reconciliation with their current partner (e.g. Dailey, Pfiester, Jin, Beck, \& Clark, 2009; Vennum, Lindstrom, Monk, \& Adams, in press), referred to as relationship cycling (Dailey, Pfiester, et al., 2009) or churning (Halpern-Meekin, Manning, Giordano, \& Longmore, 2012). Compared to couples who are stably together, couples who end and renew their relationships report lower commitment and satisfaction, poorer communication, greater uncertainty about the future of their relationship, and experience higher levels of verbal abuse and physical violence (e.g. Dailey, Middleton, \& Green, 2012; Dailey, Pfiester et al., 2009; Halpern-Meekin, Manning, Giordano, \& Longmore, 2013). Accordingly, partners in cyclical dating or cohabiting relationships who transition into marriage may be at an increased risk for marital distress and instability (Vennum et al., in press), which negatively impacts children involved in these partnerships (e.g. Kushner, 2009; Osborne \& McLanahan, 2007) and the health and well-being of the partners (e.g. Hewitt \& Turrell, 2011). Guided by the enduring dynamics model of marriage (Caughlin \& Huston, 2006; Caughlin, Huston, \& Houts, 2000; Huston, Caughlin, Houts, Smith, \& George, 2001) and using longitudinal data from 564 newlywed couples followed over the first five years of marriage, the current study examines the impact of premarital cycling on relationship dynamics across the transition to marriage.

\section{Theoretical Framework}

The enduring dynamics model of marriage posits couple interactional patterns formed during the early stages of romantic relationships persist through the transition to marriage (Caughlin \& Huston, 2006; Caughlin, Huston, \& Houts, 2000). This theory places a heavy emphasis on dyadic interactions during romantic relationship development, suggesting "the interplay between the partners' dispositions gets played out during courtship and that, as a 
consequence, the partners develop feelings and views about each other that reflect the underlying, relatively stable, psychological infrastructure of the relationship" (Huston \& Houts, 1998, p. 114). In contrast to the proposition from marital distress models that spouses enter marriage with idealized views of their unions that decline after marriage, the enduring dynamics model stems from a rational choice perspective, suggesting couples have some awareness of the strengths and weaknesses of their partner and relationship (Huston et al., 2001). Accordingly, partners' enthusiasm and hesitancy toward marriage stems from specific characteristics of their partner and relationship (Huston, 2009). Thus, partners' personal characteristics and relationship processes during courtship account for variability in marital quality across newlyweds and these differences are sustained over the course of marriage.

In support of the enduring dynamics model, Huston and colleagues (2001) found high levels of conflict with multiple breakups and reconciliations prior to marriage were related to later marital instability and courtships characterized by greater ambivalence, more negativity, and lower affection distinguished between couples in unhappy versus happy marriages (Huston, 2009). Additionally, researchers using growth mixture modeling found couples enter marriage with differing initial levels of relationship satisfaction, but the majority of couples maintain their initial level of satisfaction (Anderson, Van Ryzin, \& Doherty, 2010; Lavner \& Bradbury, 2010). Further, Lavner, Bradbury, and Karney, (2012) demonstrated differences across couples at the outset of marriage in a variety of factors known to influence marital satisfaction (e.g., stress, aggression, and attributions) are more predictive of the course of marital satisfaction than changes in those variables over time. Given the relational difficulties reported by cyclical versus non-cyclical couples (e.g. Dailey, Middleton, \& Green, 2012; Dailey, Pfiester et al., 2009; Halpern-Meekin et al., 2013; Vennum et al., in press), we conceptualize premarital cycling as a 
relationship dynamic with the potential to shape dyadic functioning across the transition to marriage.

\section{Premarital Cycling and the Early Years of Marriage}

Confidence in the decision to wed. A key distinction between dating partners who cycled and those who remained steadily together is greater uncertainty regarding the current and future status of the relationship (e.g. Dailey, Middleton, \& Green, 2012). As cyclical couples transition into cohabitation and marriage, this uncertainty does not abate. In a nationally representative sample, $34 \%$ of husbands who experienced premarital cycling planned to marry their partner prior to cohabiting in contrast to $48 \%$ of non-cyclical husbands and, once married, cyclical spouses continued to report greater uncertainty in the future of the marriage compared to non-cyclical spouses (Vennum et al., in press). Accordingly, we expect cyclical newlyweds will report less confidence in their decision to marry and will be more likely to report considering breaking off the engagement compared to non-cyclical partners.

Marital quality at the transition to marriage. Young adult dating partners who renewed their relationships report, on average, lower relationship satisfaction, more destructive conflict, and less love and understanding from their partner than non-cyclical partners (Dailey, Pfiester, et al., 2009). Interestingly, about one-third of cyclical dating partners report that the breakup and renewal improved the relationship or increased their appreciation of their relationship or partner (Dailey, Jin, Pfiester, \& Beck, 2011). Accordingly, it could be that those cyclical partners who make the transition to marriage (about one-third of those who are cyclical during courtship; Vennum et al., 2013) are those who perceive their relationship has improved and is doing well. Preliminary research, though, suggests differences in relationship quality between cyclical and non-cyclical couples are still evident after marriage (Vennum et al., in 
press). Given that cyclical cohabiting couples are more likely than non-cyclical partners to report the presence of potential constraints to ending the relationship (Vennum et al., in press), this continued difference may be due, in part, to inertia pushing less than optimal cyclical relationships through the transition to marriage (Stanley, Rhoades, \& Markman, 2006). Thus, in accordance with the enduring dynamics model, we expect that cyclical partners who transition to marriage will mirror their non-married counterparts and report a higher frequency of destructive conflict, less emotional closeness, lower satisfaction, and rate their marriages less favorably than spouses who had stable courtships.

Sustained lower satisfaction. Studies utilizing growth curve methods found marital satisfaction declines, on average, with marital duration (e.g. VanLaningham, Johnson, \& Amato, 2001) and husbands' and wives' trajectories are interrelated (Cui \& Donnellan, 2008). More recent studies employing growth mixture modeling demonstrated satisfaction follows stable trajectories for the majority of spouses (Anderson et al., 2010; Kamp Dush et al., 2008; Lavner \& Bradbury, 2010) and newlywed relationship characteristics are the best discriminators of the trajectory their relationship satisfaction will follow (Lavner et al., 2012), although no research has specifically examined the impact of premarital cycling on trajectories of marital satisfaction. Given that partners with a history of cycling report lower satisfaction prior to (e.g. Dailey, Pfiester, et al., 2009) and during marriage (Vennum et al., in press) than non-cyclical partners, we expect this difference will be evident at the transition to marriage (lower initial satisfaction) and will be sustained (e.g., parallel rate of change over time).

Further instability. In addition to continued patterns of relationship functioning, patterns of instability may also be enduring. Cycling in marriage would likely manifest through trial separations and reunions, whereas divorce would signify a permanent end to the relationship. 
Reports on the prevalence of trial separations vary greatly. Research with young adult spouses found around one third report a separation and renewal (e.g., Binstock \& Thornton, 2003); yet only $6 \%$ of spouses in a national sample of married couples reported a trial separation and were no more likely to report premarital cycling than spouses who did not experience a trial separation (Vennum et al., in press). These mixed findings do not allow for a specific hypothesis, but these data will provide additional insight into this question by exploring whether or not premarital cycling is related to trial separations during the first five years of marriage.

\section{The Present Study}

Using a large sample of newlywed couples, the current study examines the impact of premarital cycling on relationships at the transition to marriage and over the first five years of marriage. Specifically, we sought to answer three questions: 1) Do cyclical partners differ from non-cyclical partners in their desire to break off the engagement, confidence in their decision to marry, reports of destructive conflict, closeness, marriage comparison, and satisfaction at the transition to marriage? 2) How does premarital cycling influence relationship satisfaction over the early years of marriage? 3) Are couples who experienced premarital cycling more likely to experience a trial separation during the first five years of marriage than couples with stable courtships? Several control variables were explored for inclusion in the models to enhance analytic rigor: participant race, education, income, relationship length, family/friend approval of the relationship, couple religious service attendance, and depression symptoms. These variables were chosen because they represent important contextual, relational, and individual constructs that have exhibited associations in prior research with relationship satisfaction and, of particular importance to this study, stability (for reviews, see Bradbury, Fincham \& Beach, 2000; Fincham \& Beach, 2010). 
This work makes several clear contributions to the literature. First, this study expands understanding of cyclical partners' awareness of the strengths and problems in their relationship at the transition to marriage (e.g., marital comparison and thoughts of calling off the engagement), which has significant implications for premarital intervention. Second, this study is the first to prospectively explore the impact of premarital cycling on couple dynamics across the first five years of marriage in a large sample of newlywed couples. Third, the conceptual grounding in the enduring dynamics model of marriage means the results of this study contribute to further theoretical development. Indeed, relational cycling prior to marriage represents a distinct dyadic process that should have clear consequences for the future of the relationship, providing an apt test of the enduring dynamics model. If no associations are evident between premarital cycling and later relationship dynamics, this would challenge the foundation of the enduring dynamics model.

\section{Method}

\section{Procedures}

This secondary data analysis draws from a larger project, the "Marriage Matters" panel survey (Nock, Sanchez, \& Wright, 2008) that investigated the enactment of covenant marriage legislation in Louisiana. Data collection began in 1998 and three waves of data were gathered until the study was completed in 2004. Data for the first wave were gathered, on average, within six months of the couple getting married (from 0 to 12 months). Wave 2 was collected approximately 18 months later (from 12 to 24 months) and Wave 3 was gathered approximately 18 months after wave 2 (from 12 to 24 months), providing information over the first five years of marriage. Couples were recruited from seventeen randomly drawn (proportionate to size) parishes in Louisiana through filed marriage licenses (all covenant marriage licenses were drawn 
in addition to the standard marriage licenses filed immediately before and after each covenant marriage license). Questionnaires were mailed separately to husbands and wives who were instructed to complete the survey without consulting each other, yielding a $49 \%$ initial response rate $(N=707$ couples, 307 of which were covenant marriages). There were no differences between the covenant (44\%) and standard marriage (55\%) couples on the variables of interest. There was an $85 \%$ response rate at Wave 2 and a $92 \%$ response rate at Wave 3 (from at least one member of the couple). Participants were paid $\$ 10$ for completing each wave and the current analysis draws from all waves of data.

\section{Participants}

Out of the 707 couples recruited, only one partner's data were collected for 143 of the couples (21 wives did not respond and 122 husbands did not respond at any wave of data collection). These couples were dropped from our sample. The final sample included the remaining 564 couples. For 170 of these couples (30\% of the sample), at least one partner reported the couple had broken up and gotten back together at least one time during their courtship. These couples composed our cyclical sample. Table 1 contains demographic information for the cyclical $(n=170)$ and non-cyclical $(n=394)$ couples in the study.

[Table 1 about here]

\section{Measures}

The scales used in these data were not previously validated, so we conducted exploratory factor analysis (EFA) with principal axis factoring and oblique rotation to construct scales for destructive conflict, closeness, and satisfaction (Thompson, 2004). This process is explained in further detail below. The majority of the variables used in this study were assessed at Wave 1, except for trial separation (Waves 2 and 3) and marital satisfaction (Waves 1, 2, and 3). 
Premarital cycling. In order to identify newlyweds who experienced a cyclical dating relationship, participants were asked "Sometimes couples date, break up, and get back together before they get married. Other couples stay together from their first date until marriage. How about you and your partner?" Participants could respond that they never broke up, broke up and got back together once, got back together more than once, or don't remember. Partners included in the cyclical sample indicated they had either broken up and gotten back together only once (16.5\% of wives, and $16.7 \%$ of husbands) or more than one time (9.9\% of wives and $10.1 \%$ of husbands). Preliminary analysis using the Games-Howell procedure (an ANOVA post-hoc analysis used when variances across groups are unequal) revealed no significant differences in our outcome variables between those who broke up once versus more than once prior to marriage. In $7.1 \%$ of couples, only one partner reported breaking up and getting back together prior to marriage. These couples mirrored the characteristics of couples in which both partners indicated a breakup and renewal and differed from the non-cyclical couples on the variables of interest in this study. Thus, we included these couples where one partner indicated their relationship had been cyclical in the cyclical group.

Confidence in the decision to wed. Uncertainty about the decision to wed was assessed by two separate items that were negatively correlated for both cyclical $(r=-.50$ for wives and $r=$ -.40 for husbands) and non-cyclical partners ( $r=-.54$ for wives and $r=-.35$ for husbands). The first item asked, 'Sometimes people get 'cold feet' after they decide to get married. That is, sometimes people wonder whether they are doing the right thing in marrying this person at this time. Once you and your partner had decided to get married, how confident were you personally that you had made the right decision?" Participants responded with I was very unsure of the decision (1), I was somewhat unsure of the decision (2), I was mostly confident in the decision 
(3), and I was completely confident that I had made the right decision (4). Descriptive statistics were computed for cyclical (wives $M=3.45, S D=.72$ and husbands $M=3.54, S D=.68$ ) and non-cyclical (wives $M=3.64, S D=.64$ and husbands $M=3.73, S D=.54$ ) spouses. The second question asked participants to indicate whether there was ever a time that they wanted to break off the engagement to their partner. Participants indicated no (0) or yes (1).

Destructive conflict. Destructive conflict was assessed with five items that directed participants to rate how true statements were regarding what happens during disagreements on a scale from not true at all (1) to very true (3): "I feel unloved," "I get sarcastic/say things to hurt [my] partner," "My partner gets sarcastic," "I get hostile (act like we're enemies)," and "my partner gets hostile." EFA revealed the five items loaded on one factor. Mean scores were computed and higher scores indicated greater destructive conflict. Coefficient alpha and descriptive statistics were computed for cyclical (wives $\alpha=.80, M=1.63, S D=.52$ and husbands $\alpha=.75, M=1.58, S D=.47$ ) and non-cyclical (wives $\alpha=.83, M=1.47, S D=.51$ and husbands $\alpha=.78, M=1.42, S D=.44)$ spouses.

Closeness. Feelings of connectedness to one's partner were assessed with twelve items. EFA revealed a subscale of seven items assessing participants' closeness to their partner. One item was dropped due to low reliability, leaving six items: "My partner and I get closer every day," "My partner is my best friend," "My partner appreciates what I do," "I understand my partner's feelings," "I admire my partner," and "I love my partner." Responses ranged from strongly disagree (1) to strongly agree (5). Mean scores were computed and higher scores indicated greater feelings of closeness with their spouse. Coefficient alpha and descriptive statistics were computed for cyclical (wives $\alpha=.83, M=4.46, S D=.54$ and husbands $\alpha=.85, M$ 
$=4.30, S D=.62$ ) and non-cyclical (wives $\alpha=.80, M=4.57, S D=.47$ and husbands $\alpha=.77, M=$ $4.51, S D=.46)$ spouses.

Satisfaction. Participants were asked to indicate how satisfied they were on a scale from very dissatisfied (1) to very satisfied (5) with the physical intimacy, love, conflict resolution, degree of fairness, quality of communication, economic well-being, emotional intimacy, and the overall marital relationship. EFA revealed all items loaded on one factor. Mean scores were computed and higher scores indicated a greater level of satisfaction with marriage. Coefficient alpha and descriptive statistics were computed for cyclical (wives $\alpha=.87, M=3.94, S D=.75$ and husbands $\alpha=.88, M=3.88, S D=.73$ ) and non-cyclical (wives $\alpha=.84, M=4.20, S D=.63$ and husbands $\alpha=.85, M=4.15, S D=.63$ ) spouses.

Marriage comparison. Participants were asked if they consider their marriage to be much worse than most (0), somewhat worse than most (1), about the same as most other marriages (2), somewhat better than most (3) or much better than most (4). Descriptive statistics were computed for cyclical (wives $M=3.30, S D=.80$ and husbands $M=3.28, S D=.77$ ) and non-cyclical (wives $M=3.49, S D=.79$ and husbands $M=3.49, S D=.69$ ) spouses.

Trial separation. One item assessed whether partners experienced a trial separation: "People sometimes leave home for a short time as a trial separation because of problems they are having with their marriage. Has this ever happened in your marriage?" Participants indicated yes (1), no (2), or I don't know (3). The response of I don't know was recoded as missing data. Couples where at least one partner reported a trial separation were labelled as having experienced a trial separation.

Control Variables. Although several controls were considered for inclusion in the analyses (income, relationship length, the presence of children, couple religious service 
attendance, family/friend approval of the marriage, and depression symptoms), only depression and family/friend approval of the marriage accounted for unique variance in the dependent variables during preliminary analyses, so these were retained (the rest were removed for parsimony).

Individual depression symptoms were assessed by the mean of 12 items from the Center for Epidemiologic Studies-Depression scale (CES-D; Radloff, 1977) concerning ways the participant "might have felt or behaved during the past week." Sample items include, "Feel that you could not shake off the blues even with help from your family or friends?" and "Feel lonely?" Responses ranged from none (0) to 7 days (7). Coefficient alpha and descriptive statistics were computed for cyclical (wives $\alpha=.85, M=1.25, S D=1.25$ and husbands $\alpha=.89$, $M=.77, S D=.93$ ) and non-cyclical (wives $\alpha=.71, M=1.00, S D=1.07$ and husbands $\alpha=.90$, $M=.77, S D=1.02)$ spouses.

Family/friend approval of the marriage was assessed by asking: "When you and your partner first announced that you were getting married, did the following people generally approve or disapprove of the marriage?" Participants indicated the degree to which their father, mother, brothers and sisters, and friends approved, ranging from strongly disapproved (1) to strongly approved (4). Mean scores were calculated. Coefficient alpha and descriptive statistics were computed for cyclical (wives $\alpha=.85, M=3.45, S D=.61$ and husbands $\alpha=.87, M=3.43$, $S D=.57$ ) and non-cyclical (wives $\alpha=.71, M=3.52, S D=.48$ and husbands $\alpha=.82, M=3.54$, $S D=.48)$ spouses

\section{Results}

\section{Newlywed Characteristics}


Analyses comparing the characteristics of cyclical and non-cyclical spouses at the transition to marriage were conducted in SPSS using listwise deletion since we had little missing data $(1.8 \%)$ at Wave 1 . Because our data were nonindependent (see Kenny, Kashy, \& Cook, 2006) and our primary interest was the differences between cyclical and non-cyclical partners rather than between the members of each couple, we first analyzed husbands' and wives' desire to break off the engagement separately in order to control for gender. As expected, a greater percentage of cyclical spouses (27.8\% of wives and $22.6 \%$ of husbands) wanted to break off the engagement compared to non-cyclical spouses $\left(14.5 \%\right.$ of wives and $8.4 \%$ of husbands $\left(\chi_{\text {wives }}^{2}[1\right.$, $\left.N=530]=13.08, p<.001, \varphi=.16 ; \chi_{\text {hubands }}^{2}[1, N=528]=20.34, p<.001, \varphi=.20\right)$.

To examine the impact of premarital cycling on newlywed relationship characteristics, we next used the regression procedure suggested by Kenny et al. (2006) for use with nonindependent data. Two regressions were run for each dependent variable to examine the main effect of gender (first regression models) and cycling (second regression models) on spouses' confidence in the decision to marry, closeness, destructive conflict, satisfaction, and comparison of their marriage to others' while controlling for depression and family/friend approval (all variables assessed at Wave 1).

In the first regression models, the difference between wives' and husbands' scores was calculated for each relationship characteristic at the transition to marriage. This difference score was then used as the outcome variable in order to test the main effect of gender (the intercept) and the interaction of gender with cycling. Results indicated husbands reported more confidence in their decision to wed than wives, whereas wives reported greater feelings of closeness and satisfaction than their husbands. The difference between husbands' and wives' scores on the variables of interest did not differ as a result of premarital cycling, although depression 
symptoms were associated with a larger difference between spouses' scores on all dependent variables, and approval from friends and family was associated with a smaller difference between spouses' scores on closeness and confidence in the decision to wed.

Of greater interest, we next examined the main effect of cycling by using the sum of spouses' scores on each variable as the outcome (Kenny et al., 2006). Model $R^{2}$ is reported along with Pearson and semi-partial correlations to indicate the unique contribution of each independent variable. Results revealed spouses who experienced a breakup and renewal prior to marriage reported less confidence in their decision to marry, less closeness to their partner, higher rates of destructive conflict, lower relationship satisfaction, and rated their marriages less favorably compared to others than spouses without a history of cycling, controlling for family and friend approval of the marriage and depressive symptoms (see Table 2).

[Table 2 about here]

\section{Over the First Five Years}

To determine whether premarital cycling influences relationship satisfaction over the early years of marriage, we estimated dyadic parallel process latent growth curves in Mplus 7.1 (Muthén \& Muthén, 1998-2012), controlling for family/friend approval of the relationship and depression symptoms. Destructive conflict at Wave 1 was also included as a control variable in light of evidence that negative conflict is a robust predictor of marital satisfaction over time (Bradbury et al., 2000). Dyadic parallel process growth curve modeling estimates the rate of change for husbands and wives while accounting for the partners' change, thus addressing the nonindependence in the data. Missing data was handled with the full-information maximum likelihood procedure, which ranged from $1.8 \%$ at Wave 1 to $35.5 \%$ at Wave 3. 
After first computing univariate growth curves for husbands and wives, a parallel process growth curve model was conducted to examine husbands' and wives' trajectories of marital satisfaction without any predictor variables included. The variable loadings on the intercept were each fixed to 1 and the loading of Wave 1 on slope was fixed at 0 , Wave 2 was fixed at 1 , and Wave 3 was fixed at 2 to specify a linear trend. According to guidelines from $\mathrm{Hu}$ and Bentler (1999), this growth curve proved an excellent fit to the data: $\chi^{2}(4)=2.51 ;$ RMSEA $=.00 ; \mathrm{CFI}=$ $1.0 ; \mathrm{TLI}=1.0 ; \mathrm{SRMR}=.02$. This growth curve indicated wives' initial score was 4.12 and declined by .21 units at each wave and husbands' initial score was 4.07 and declined by .13 points at each wave. There was significant variance in wives' slope, wives' intercept, and husbands' intercept, but not husbands' slope.

We then proceeded to our final analysis in which cycling was added as a predictor of husbands' and wives' satisfaction at the transition to marriage (their intercepts) and their rate of change over the first five years of marriage (their slopes), controlling for family/friend approval of the relationship, depression symptoms, and destructive conflict at Wave 1 (see Figure 1 for fit indices and parameter estimates). This model fit the data well and husbands' and wives' initial marital satisfaction positively covaried, as did their rate of change. As expected, experiencing premarital cycling predicted lower marital satisfaction for husbands and wives at Wave 1 (intercept), but was not related to changes in satisfaction over time (slope). For the control variables, family and friend approval was related to higher marital satisfaction at the transition to marriage (Wave 1) while destructive conflict and depression symptoms were associated with lower satisfaction for husbands' and wives. Destructive conflict predicted a steeper rate of decline in satisfaction for husbands and wives and depression symptoms were associated with a steeper decline for wives. 
[Figure 1 about here]

Trial separations. We next examined whether spouses who had cyclical courtships were more likely to continue cycling in their marriage. Overall, our sample had few divorces $(n=36)$ over the first five years of marriage (divorce was not related to premarital cycling), but 66 couples reported they engaged in a trial separation. Couples who experienced premarital cycling were more likely to experience a trial separation than non-cyclical couples, with almost $16 \%$ of couples who experienced premarital cycling reporting a trial separation within the first five years of marriage compared with only about $10 \%$ of their non-cyclical counterparts $\left(\chi^{2}[1, N=564]=\right.$ 4.12, $p<.05, \varphi=.09)$, although the effect was small.

\section{Discussion}

The enduring dynamics model of marriage suggests couple patterns of behavior and interaction are formed during the early stages of romantic relationships and persist into marriage (Caughlin \& Huston, 2006; Caughlin, Huston, \& Houts, 2000). Partners in cyclical dating and cohabiting relationships consistently report more destructive conflict, more uncertainty, and less satisfaction in their relationships (Dailey, Pfiester, et al., 2009; Vennum et al., in press). According to the enduring dynamics model, should these cyclical courtships transition into marriage, these spouses may be at greater risk for distress and instability than spouses who did not experience instability during courtship. Although previous cross-sectional support for the negative impacts of cycling during courtship on marriage have been found (Vennum et al., in press), researchers had yet to explore cyclical relationships at the transition to marriage, a key point for intervention (e.g. Hawkins, Carroll, Doherty, \& Willoughby, 2004). This study extends the literature on relationship cycling by examining the impact of premarital cycling on the entrance into marriage and relationship dynamics over the first five years. 
The recurrent theme of our results is that premarital cycling has small, yet robust, effects on marital characteristics at the outset of marriage and over the first five years. Although it is possible that cyclical couples who make the transition into marriage are less distressed than those cyclical couples who do not (a topic for future research), the differences between cyclical and non-cyclical newlyweds mirrored the findings with dating and cohabiting couples; namely, the cyclical couples exhibited poorer relationship adjustment across a variety of constructs compared to their non-cyclical counterparts (e.g. Dailey, Pfiester, et al., 2009). Six months after marrying, cyclical partners reported greater conflict and uncertainty and less closeness and satisfaction than newlyweds without a history of cycling and these lower levels of satisfaction were sustained over the first five years for cyclical couples. Although premarital cycling does not "tell the whole story" of how satisfied a newlywed couple is in their marriage, cyclical couples tend to be less satisfied than couples without a history of cycling even after accounting for the level of destructive conflict, whether their friends and family approve of their marriage, and depression symptoms. While the magnitude of many associations between cycling and the variables in this study are small, the aggregated effect of premarital cycling on each of these domains likely results in a meaningful impact on these relationships.

Although one third of cyclical dating partners believe cycling improved their relationship or gave them a new appreciation for their relationship/partner (Dailey et al., 2011), on average, cyclical partners who transition to marriage are in greater distress than non-cyclical partners and are aware of this difference. In accordance with the enduring dynamics model (Huston et al., 2001), nearly one-third of cyclical partners considered calling off their engagement and reported less confidence in their decision to wed than non-cyclical couples. These doubts are not benign; research demonstrates experiencing "cold feet" or a lack of confidence around the decision to 
wed continues to extract a toll on dyadic functioning years into marriage, exhibiting longitudinal associations with higher rates of divorce, lower relationship satisfaction, and less time spent together (Johnson \& Anderson, 2013; Lavner, Karney, \& Bradbury, 2012). Wilson and Huston (2013) suggest that although intimate partners evaluate strengths and weaknesses in their relationship from the same data, partners' assessments can differ, resulting in discordant decisions and further ambivalence. Findings from dating couples suggest cyclical couples may be especial prone to struggle with being on the same page during decisions to end and renew their relationships (e.g. Dailey et al., 2011). The lack of a shared reality may mean partners are not receiving confirmation of their beliefs about the long-term viability of the relationship (Wilson \& Huston, 2013). Accordingly, cyclical partners' greater ambivalence did not abate post-wedding in the current study, with cyclical newlyweds holding a less favorable view of their marriage compared to others' than non-cyclical newlyweds.

Finally, newlyweds who cycled prior to marriage were more likely to cycle, in the form of trial separations, during the first five years of marriage than newlyweds who never experienced a breakup and renewal prior to marriage, providing direct support for the enduring dynamics model. Estimates suggest only one third of couples who have a trial separation reconcile and half of those who reconcile separate again within three years (Binstock \& Thornton, 2003). Interestingly, couples in our sample who were cyclical prior to marriage were not more likely to divorce than those who never ended and renewed their relationships. Huston and colleagues (2001) found that although the enduring dynamics model explained quick divorces (within two years of marriage) and differences in later satisfaction among couples who stayed married, disillusionment processes distinguished between couples who divorced after two or more years of marriage from those who did not. Regardless of where they entered marriage, 
couples who later divorced experienced sharp declines in love and affection paired with increased ambivalence; whereas, stability in feelings, behaviors, and beliefs about the relationship characterized marriages that continued (Huston et al., 2001). The lower relationship quality and patterns of time apart are not a departure from the previous trajectory of the relationship for cyclical partners, perhaps indicating that cyclical partners are more likely to enter marriage with lower expectations and endure in unhappy marriages than partners who entered marriage with more room to become disillusioned. This perspective challenges conceptualizations of stability as it applies to cyclical relationships where continuing patterns of distress, breakup, and renewal represent a stable state across time. This possibility is supported with the current data spanning the first five years of marriage, but deserves further investigation across a larger time span.

Although we hope the cyclical relationships that transition to marriage are those which have improved to the level of those couples who never cycled, our results indicate this is not the case. Although these couples are likely aware of the difficulties present in their relationships, as proposed by the enduring dynamics model (Huston et al., 2001), partners with a history of cycling may be more likely to endure in distressed relationships than non-cyclical partners due to constraints that make the relationship hard to permanently end (see Stanley et al., 2006). In young adult dating relationships, for example, feeling lonely and not having alternative partners to date during the breakup (Dailey, et al., 2011) constitute perceived constraints preventing a permanent end to the relationship (Rhoades, Stanley, \& Markman, 2010). In cohabiting relationships, material constraints such as cyclical partners' greater likelihood of reporting financial stressors, the presence of children (Vennum et al., in press), and higher intimate selfdisclosure (Halpern-Meekin et al., 2012) may contribute to partners renewing a less than optimal 
relationship (Rhoades et al., 2010). Dedication motivates partners to act in the best interest of the relationship. When partners accrue constraints to ending the relationship before dedication is fully developed, the chances of distress increase because partners persist in a relationship to which they are yet to fully commit (Stanley et al., 2006). Unfortunately, cyclical partners report lower dedication, greater uncertainty, and poorer communication than non-cyclical partners (e.g. Dailey, Pfiester et al., 2009), suggesting cyclical partners may be especially prone to accrue constraints before their dedication has developed.

\section{Implications for Practice}

These results have several clear implications for clinicians and relationship educators. The enduring dynamics model suggests "the ultimate fate of the relationship is largely determined before the marriage" (Caughlin \& Huston, 2006, p. 137), supporting the premise that it is possible to identify couples at risk for marital distress and instability prior to marriage. As such, these results highlight the opportunity for early intervention. For cyclical couples, the signs of distress are likely already present during courtship (e.g., Dailey, Pfiester et al., 2009; HalpernMeekin et al., 2013). Rhoades and Stanley (2009) recommend focusing on relationship education for individuals well before they commit to marriage in order to impact risk-factors for distress and divorce that become static as partners transition into further relationship stages (i.e., constraints associated with relationship transitions). For example, Within My Reach (Pearson, Stanley, \& Rhoades, 2008), a curriculum designed for individuals who have not yet committed to a relationship, has an emphasis on the impact of relationships on children, safety in romantic relationships, and factors to consider when making decisions around relationship transitions. The greater ambiguity, conflict, and violence (e.g., Dailey, Pfiester et al., 2009; Halpern-Meekin et al., 2013) found in cyclical relationships suggest open discussion about the consequences of 
moving through relationship transitions may clarify the risks associated with subsequent transitions for individuals with experience in cyclical relationships. Thus, intervening early, when signs of distress first arise and before constraints accrue, may optimize the effectiveness of efforts to stabilize couples and the families they form (Rhoades \& Stanley, 2009).

It is important that practitioners assess for relationship cycling and the dynamics commonly reported by these couples that place them at risk for further distress to bolster interventions for these couples. Findings of this study and previous research (Vennum et al., in press) suggest between one fifth and one third of couples may be proceeding into marriage with a history of relationship cycling. Given the high percentage of individuals in cyclical relationships who considered calling off their engagement, serious discussion to clarify each partner's confidence in the decision to wed, perceptions of potential risks to their future marriage, and immediate actions to improve their relationship or end the relationship in a healthy way is an important course of action for practitioners. Accordingly, traditional premarital education curricula that focus on reducing dangerous communication patterns and increasing positive interactions and commitment (such as Prevention and Relationship Enhancement Program [PREP]; see Markman, Stanley, \& Blumberg, 2010) and relationship self-regulation (such as Couple CARE; see Halford, Lizzio, Wilson, \& Occhipinti, 2007) may be particularly beneficial if augmented with an emphasis on the risks associated with relationship cycling.

\section{Strengths and Limitations}

This study has a number of important strengths. First, this study is the first to examine the impact of premarital cycling on relationship functioning over the first five years of marriage while also controlling for several robust predictors. Second, the large sample of couples provided enough statistical power to detect a number of small, but meaningful effects relationship cycling 
exhibited on the outcome variables. Third, the use of dyadic parallel process growth curves to model the interrelated trajectories of spouses' marital satisfaction over the first five years of marriage is a clear strength. Several previous studies analyzing trajectories of marital satisfaction with dyadic data separated husbands and wives for the analyses (Lavner \& Bradbury, 2010; Lavner et al., 2012) which results in the loss of an essential piece of data: the partner's trajectory. We are aware of only one other study that explicitly modeled marital satisfaction trajectories through the use of dyadic parallel process modeling (Cui \& Donnellan, 2009). Undoubtedly, increased precision in understanding how satisfaction changes over time within a relationship will remain a focus for intimate relationship scholars and approaches that account for the relatedness in partners' trajectories and the exploration of multiple, distinct trajectories are essential for gaining precision.

There are also several limitations to this study. The current survey did not ask about cycling in previous relationships, so we were not able to assess the impact of prior cycling on the current relationship. We did not have data past the first five years of marriage, limiting our ability to explore whether the observed patterns in early marriage are sustained further. Also, questionnaires were mailed, so although partners were instructed to complete their questionnaires separately, we have no guarantee that they did. Finally, the constructs of interest in this study were not operationalized through pre-existing, validated measures. Accordingly, several of our constructs were assessed with only one item, which does not produce the same level of variability in responses that multiple-item scales would. This is a common issue in secondary data analysis, resulting in less precise measurement of constructs than desired, but must be considered in light of potential strengths arising from such an analysis (i.e., utilization of a large, longitudinal study of couples). The measures in this study possessed adequate reliability, face 
validity, and loaded onto one factor using exploratory factor analysis. Thus, we expect replication of these findings with more robust measurement might lead to greater effect sizes. Future Directions

Although a challenging endeavor, following partners over time from young adulthood through transitions to marriage and childbearing would provide a richer understanding of the developmental precursors to cycling in relationships, factors that distinguish cyclical couples who transition into marriage versus those who do not, and how the transition to parenthood impacts and is impacted by relationship cycling. This would require researchers to shift conceptualizations of intimate relationships as either being "together" or "broken up," as these categories may not accurately represent cycling. Further, following individuals over time may yield larger effect sizes between cyclical and non-cyclical groups since the couples in which both partners respond may be reflective of couples who are doing better than others and allow researchers to assess the individual characteristics associated with relationship cycling.

As has been argued in the marriage and divorce literature (e.g., Fincham, Stanley, \& Beach, 2007), more research is needed on the positive interpersonal processes (e.g. forgiveness, sacrifice) that may neutralize the negative effects of poor communication and other challenges that place cyclical couples at risk for further relationship distress and instability. Many factors associated with relationship satisfaction, distress, and instability (such as infidelity, domestic violence, etc.) are yet to be examined among cyclical couples and represent an area ripe for investigation (see Amato, 2010). Continued exploration of this topic will provide a more comprehensive understanding of premarital cycling and the health and well-being of partners and children involved in these relationships.

\section{Conclusion}


Guided by the enduring dynamics model of marriage, the purpose of this study was to examine the impact of premarital cycling on relationship dynamics at the entrance into marriage and over the first five years. Results demonstrated cyclical couples exhibit worse adjustment on a variety of relationship indicators at the entrance to marriage compared to couples without a history of cycling during courtship. Reduced relationship satisfaction and continued cycling, as evidenced by the presence of trial separations, were still evident five years into the marriage for cyclical couples. Coupled with the extant literature, these results provide strong evidence that a courtship characterized by breakups and renewals represents a relational vulnerability with implications extending years into the future. Premarital cycling represents a chapter in a couple's biography with the ability to foreshadow couple functioning half a decade into marriage, at least. 


\section{References}

Anderson, J. R., Van Ryzin, M. J., \& Doherty, W. J. (2010). Developmental trajectories of marital happiness in continuously married individuals: A group-based modeling approach. Journal of Family Psychology, 24, 587-596. doi: 10.1037/a0020928

Binstock, G., \& Thornton, A. (2003). Separations, reconciliations, and living apart in cohabiting and marital unions. Journal of Marriage and Family, 65, 432-443. doi: 10.1111/j.1741-3737.2003.00432.x

Bradbury, T. N., Fincham, F. D., \& Beach, S. R. H. (2000). Research on the nature and determinants of marital satisfaction: A decade in review. Journal of Marriage and the Family, 62, 964-980. doi: 10.1111/j.1741-3737.2000.00964.x

Caughlin, J. P., \& Huston, T. L. (2006). The affective structure of marriage. In A. L. Vangelisti \& D. Perlman (Eds.), Cambridge handbook of personal relationships (pp. 131-156). New York, NY: Cambridge University Press.

Caughlin, J. P., Huston, T. L., \& Houts, R. M. (2000). How does personality matter in marriage?: An examination of trait anxiety, interpersonal negativity, and marital satisfaction. Journal of Personality and Social Psychology, 78, 326-336. doi: 10.1037/0022-3514.78.2.326

Cui, M., \& Donnellan, M. B. (2009). Trajectories of conflict over raising adolescent children and marital satisfaction. Journal of Marriage and Family, 71, 478-494. doi: 10.1111/j.17413737.2009.00614.x

Dailey, R. M., Jin, B., Pfiester, A., \& Beck, G. (2011). On-again/off-again dating relationships: What keeps partners coming back? The Journal of Social Psychology, 151, 417- 440. doi: $10.1080 / 00224545.2010 .503249$

Dailey, R. M., Pfiester, A., Jin, B., Beck, G., \& Clark, G. (2009). On-again/off-again dating 
relationships: How are they different from other dating relationships? Personal Relationships, 16, 23-47. doi: 10.1111/j.1475-6811.2009.01208.x

Fincham, F. D., \& Beach, S. R. H. (2010). Marriage in the new millennium: A decade in review. Journal of Marriage and Family, 72, 630-649. doi: 10.1111/j.1741-3737.2010.00722.x

Fincham, F.D., Stanley, S., \& Beach, S. R. H. (2007).Transformative processes in marriage: An analysis of emerging trends. Journal of Marriage and the Family, 69, 275-292. doi: 10.1111/j.1741-3737.2007.00362.x

Halford, W. K., Lizzio, A., Wilson, K. L., Occhipinti, S. (2007). Does working on your relationship help?: Couple relationship self-regulation and satisfaction in the first 4 years of marriage. Journal of Family Psychology, 21, 185-194. doi: 10.1037/08933200.21 .2 .185

Halpern-Meekin, S., Manning, W. D., Giordano, P. C., \& Longmore, M. A. (2012). Relationship churning in emerging adulthood: On/off relationships and sex with an ex. Journal of Adolescent Research, 28, 166-188. doi: 10.1177/0743558412464524

Halpern-Meekin, S. Manning, W. D., Giordano, P. C., \& Longmore, M. A. (2013). "Relationship churning, physical violence, and verbal abuse in young adult relationships.” Journal of Marriage and Family 75, 2-12. doi: 10.1111/j.1741-3737.2012.01029.x

Hewitt, B. \& Turrell, G. (2011). Short-term functional health and well-being after marital separation: Does initiator status make a difference? American Journal of Epidemiology, 173, 1308-1318 . doi: 10.1093/aje/kwr007

Hu, L., \& Bentler, P. M. (1999). Cutoff criteria for fit indexes in covariance structure analysis: Conventional criteria versus new alternatives. Structural Equation Modeling, 6, 1-55. doi: $10.1080 / 10705519909540118$ 
Huston, T. L. (2009). What's love got to do with it? Why some marriages succeed and others fail. Personal Relationships, 16, 301-327. doi: 10.1111/j.1475-6811.2009.01225.x

Huston, T. L., Caughlin, J. P., Houts, R. M., Smith, S. E., \& George, L. J. (2001). The connubial crucible: Newlywed years as predictors of marital delight, distress, and divorce. Journal of Personality and Social Psychology, 80, 237-252. doi: 10.1037/0022-3514.80.2.237

Huston, T. L., \& Houts, R. M. (1998). The psychological infrastructure of courtship and marriage: The role of personality and compatibility in the evolution of romantic relationships. In T. Bradbury (Ed), The developmental course of marital dysfunction (pp.114-151). New York, NY: Cambridge university Press.

Johnson, M. D., \& Anderson, J. R. (2013). The longitudinal association of marital confidence, time spent together, and marital satisfaction. Family Process, 52, 244-256. doi: 10.1111/ j.1545-5300.2012.01417.x

Kenny, D. A., Kashy, D. A., \& Cook, W. L. (2006). Dyadic data analysis. New York: Cambridge University Press.

Kline, R. B. (2010). Principles and practice of structural equation modeling ( ${ }^{\text {rd }}$ ed.). New York: Guilford Press.

Kushner, M. A. (2009). A review of the empirical literature about child development and adjustment post-separation. Journal of Divorce and Remarriage, 50, 496-516. doi: $10.1080 / 10502550902970595$

Lavner, J. A., \& Bradbury, T. N. (2010). Patterns of change in marital satisfaction over the newlywed years. Journal of Marriage and Family, 72, 1171-1187. doi: 10.1111/j.17413737.2010.00757.x

Lavner, J. A., Bradbury, T. N., \& Karney, B. R. (2012). Incremental change or initial 
differences? Testing two models of marital deterioration. Journal of Family Psychology, 26, 606-616. doi: 10.1037/a0029052

Lavner, J. A., Karney, B. R., \& Bradbury, T. N. (2012). Do cold feet warn of trouble ahead? Premarital uncertainty and four-year marital outcomes. Journal of Family Psychology, 26, 1012-1017. doi: 10.1037/a0029912

Markman, H. J., Rhoades, G. K., Stanley, S. M., Ragan, E. P., \& Whitton, S. W. (2010). The premarital communication roots of marital distress: The first five years of marriage. Journal of Family Psychology, 24, 289-298.

Markman, H., Stanley, S., \& Blumberg, S. (2010). Fighting for your marriage (3 ${ }^{\text {rd }}$ ed.). San Francisco, CA: Jossey-Bass.

Marsh, H.W., Hau, K-T., \& Wen, Z. (2004). In search of golden rules: comment on hypothesis testing approaches to setting cutoff values for fit indexes and dangers in overgeneralizing Hu and Bentler's (1999) findings. Structural Equation Modeling, 11, 320-341. doi: 10.1207/s15328007sem1103_2

Muthén, L. K., \& Muthén, B. O. (1998-2012). Mplus user's guide (5 ${ }^{\text {th }}$ ed.). Los Angeles: Authors

Nock, S. L., Sanchez, L. A., \& Wright, J. D. (2008). Covenant Marriage: The Movement to Reclaim Tradition in America. Piscataway, NJ: Rutgers University Press.

Osborne, C., \& McLanahan, S. (2007). Partnership instability and child-well-being. Journal of Marriage and Family, 69, 1065-1083. doi: 10.1111/j.1741-3737.2007.00431.x

Pearson, M., Stanley, S., \& Rhoades, G. (2008). Within My Reach instructor manual. Denver, CO: PREP, Inc.

Radloff, L. S. (1977). The CES-D scale: A self-report depression scale for research in the general 
population. Applied Psychological Measurement, 1, 384-401.

Rhoades, G. \& Stanley, S. (2009). Relationship education for individuals: The benefits and challenges of intervening early. In H. Benson and S. Callan (Eds.), What works in relationship education: Lessons from academics and service deliverers in the United States and Europe (pp. 45 - 54). Doha, Qatar: Doha International Institute for Family Studies and Development.

Rhoades, G., Stanley, S. M., \& Markman, H. J. (2010). Should I stay or should I go? Predicting dating relationship stability from four aspects of commitment. Journal of Family Psychology, 24, 543-550. doi: 10.1037/a0021008

Sassler, S., Miller, A. J. (2011). Class differences in cohabitation processes. Family Relations, 60, 163-177. doi: 10.1111/j.1741-3729.2010.00640.x

Stanley, S. M., Rhoades, G. K., \& Markman, H. J. (2006). Sliding versus deciding: Inertia and the premarital cohabitation effect. Family Relations, 55, 499-509. doi:10.1111/j.17413729.2006.00418.x

Thompson, B. (2004). Exploratory and confirmatory factor analysis; understanding concepts and applications. Washington, DC: American Psychological Association.

VanLaningham, J., Johnson, D. R., \& Amato, P. (2001). Marital happiness, marital duration, and the u-shaped curve: Evidence from a five-wave panel study. Social Forces, 79, 13131341. doi: $10.1037 / \mathrm{a} 0017578$

Vennum, A., Lindstrom, R., Monk, J. K., \& Adams, R. (in press) "It's complicated": The continuity and correlates of cycling in cohabiting and marital relationships. Journal of Social and Personal Relationships. Advance online publication. doi:

$10.1177 / 0265407513501987$ 
Table 1

Description of Sample Demographics

\begin{tabular}{|c|c|c|c|c|}
\hline \multirow[b]{2}{*}{ Variable } & \multicolumn{2}{|c|}{ Cyclical $(n=170)$} & \multicolumn{2}{|c|}{ Non-Cyclical $(n=394)$} \\
\hline & Husband & Wife & Husband & Wife \\
\hline Age & $\begin{array}{c}29.30 \\
(10.22)\end{array}$ & $\begin{array}{c}27.67 \\
(8.81)\end{array}$ & $\begin{array}{c}33.40 \\
(10.54)\end{array}$ & $\begin{array}{c}28.74 \\
(9.22)\end{array}$ \\
\hline \multicolumn{5}{|l|}{ Race } \\
\hline European American & $80.6 \%$ & $75.9 \%$ & $82.2 \%$ & $82.0 \%$ \\
\hline African American & $14.7 \%$ & $14.7 \%$ & $13.5 \%$ & $11.9 \%$ \\
\hline Latino/a & $1.8 \%$ & $4.8 \%$ & $1.4 \%$ & $2.4 \%$ \\
\hline Other race & $2.9 \%$ & $4.8 \%$ & $3.1 \%$ & $3.9 \%$ \\
\hline \multicolumn{5}{|l|}{ Education } \\
\hline Less than High School & $7.1 \%$ & $4.8 \%$ & $7.2 \%$ & $5.1 \%$ \\
\hline High School Diploma/ GED & $39.3 \%$ & $35.9 \%$ & $37.0 \%$ & $31.8 \%$ \\
\hline Some College/Bachelor's Degree & $44.0 \%$ & $47.9 \%$ & $47.6 \%$ & $56.2 \%$ \\
\hline Graduate School & $9.6 \%$ & $11.4 \%$ & $8.2 \%$ & $6.9 \%$ \\
\hline \multicolumn{5}{|l|}{ Income } \\
\hline Less than $\$ 30,000$ & $51.5 \%$ & $77.4 \%$ & $53.6 \%$ & $76.5 \%$ \\
\hline$\$ 30,000-\$ 59,999$ & $42.4 \%$ & $19.4 \%$ & $36.5 \%$ & $21.4 \%$ \\
\hline$\$ 60,000$ and Above & $6.1 \%$ & $3.2 \%$ & $9.9 \%$ & $2.1 \%$ \\
\hline \multicolumn{5}{|l|}{ Employment } \\
\hline Full Time Work & $81.2 \%$ & $59.4 \%$ & $79.2 \%$ & $61.6 \%$ \\
\hline Part Time Work & $7.1 \%$ & $12.9 \%$ & $9.9 \%$ & $14.0 \%$ \\
\hline In School & $2.4 \%$ & $6.5 \%$ & $2.0 \%$ & $6.1 \%$ \\
\hline Homemaker & $0 \%$ & $10.6 \%$ & $0 \%$ & $9.9 \%$ \\
\hline Other & $9.5 \%$ & $10.6 \%$ & $8.9 \%$ & $8.4 \%$ \\
\hline
\end{tabular}


Table 2

Summed Dyadic Regression Analyses for Married Partners

\begin{tabular}{|c|c|c|c|c|c|c|c|c|c|c|c|c|c|c|c|c|c|c|c|c|}
\hline \multirow[b]{2}{*}{ Variable } & \multicolumn{4}{|c|}{ Marriage Confidence } & \multicolumn{4}{|c|}{ Closeness } & \multicolumn{4}{|c|}{ Destructive Conflict } & \multicolumn{4}{|c|}{ Relationship Satisfaction } & \multicolumn{4}{|c|}{ Marriage Comparison } \\
\hline & $B$ & $S E B$ & $\beta$ & $r, r_{s p}$ & $B$ & $S E B$ & $\beta$ & $r, r_{s p}$ & $B$ & $S E B$ & $\beta$ & $r, r_{s p}$ & $B$ & $S E B$ & $\beta$ & $r, r_{s p}$ & $B$ & $S E B$ & $\beta$ & $r, r_{s p}$ \\
\hline Constant & $4.94 * *$ & .34 & & & $7.42 * *$ & .30 & & & $3.19 * *$ & .32 & & & $6.72 * *$ & .41 & & & $5.87 * *$ & .47 & & \\
\hline Cycling & $-.28 * *$ & .08 & -.13 & $-.18,-.13$ & $-.20 * *$ & .07 & -.11 & $-.15,-.10$ & $.23 * *$ & .07 & .12 & $.15, .12$ & $-.38 * *$ & .10 & -.15 & $-.18,-.14$ & $-.33 * *$ & .11 & -.12 & $-.15,-.12$ \\
\hline W FFapp & $.28 * *$ & .08 & .15 & $.28, .14$ & $.27 * *$ & .07 & .16 & $.30, .15$ & -.00 & .07 & -.00 & $-.12,-.02$ & $.28 * *$ & .09 & .12 & $.26, .11$ & .17 & .11 & .07 & $.18, .07$ \\
\hline H FFapp & $.46^{* *}$ & .08 & .25 & $.35, .23$ & $.29 * *$ & .07 & .17 & $.31, .15$ & $-.17 *$ & .07 & -.10 & $-.19,-.09$ & $.33^{* *}$ & .09 & .14 & $.28, .13$ & $.28 * *$ & .11 & .11 & $.22, .10$ \\
\hline W Dep & $-.08 *$ & .04 & -.10 & $-.24,-.09$ & $-.15 * *$ & .03 & -.20 & $-.35,-.18$ & $.17 * *$ & .03 & .22 & $.32, .20$ & $-.25 * *$ & .04 & -.23 & $-.38,-.21$ & $-.21 * *$ & .05 & -.18 & $-.31,-.17$ \\
\hline H Dep & $-.12 * *$ & .04 & -.12 & $-.20,-.11$ & $-.21 * *$ & .04 & -.24 & $-.34,-.22$ & $.20 * *$ & .04 & .23 & $.31, .22$ & $-.32 * *$ & .05 & -.26 & $-.36,-.25$ & $-.32 * *$ & .06 & -.24 & $-.32,-.23$ \\
\hline$R^{2}$ & \multicolumn{4}{|c|}{.20} & \multicolumn{4}{|c|}{.27} & \multicolumn{4}{|c|}{.18} & \multicolumn{4}{|c|}{.28} & \multicolumn{4}{|c|}{.18} \\
\hline$F$ & \multicolumn{4}{|c|}{$26.96 * *$} & \multicolumn{4}{|c|}{$38.56 * *$} & \multicolumn{4}{|c|}{$23.19 * *$} & \multicolumn{4}{|c|}{$41.74 * *$} & \multicolumn{4}{|c|}{$24.22 * *$} \\
\hline
\end{tabular}

Note. Husbands' (H) and wives' (W) scores were summed to create the dyadic scale score. Cycling is dummy coded such that cycling $=1$. W FFapp

= approval of the marriage by wives' friends and family. H FFapp = approval of the marriage by Husbands' friends and family. W Dep $=$ Wives'

depressive symptoms. H Dep = Husbands' depressive symptoms.

$* p<.05 . * * p<.01$. 
Figure 1

Dyadic Growth Curve Model with Cycling Predicting Husbands' and Wives' Marital

Satisfaction Across the Transition to Marriage ( $n=564$ couples)

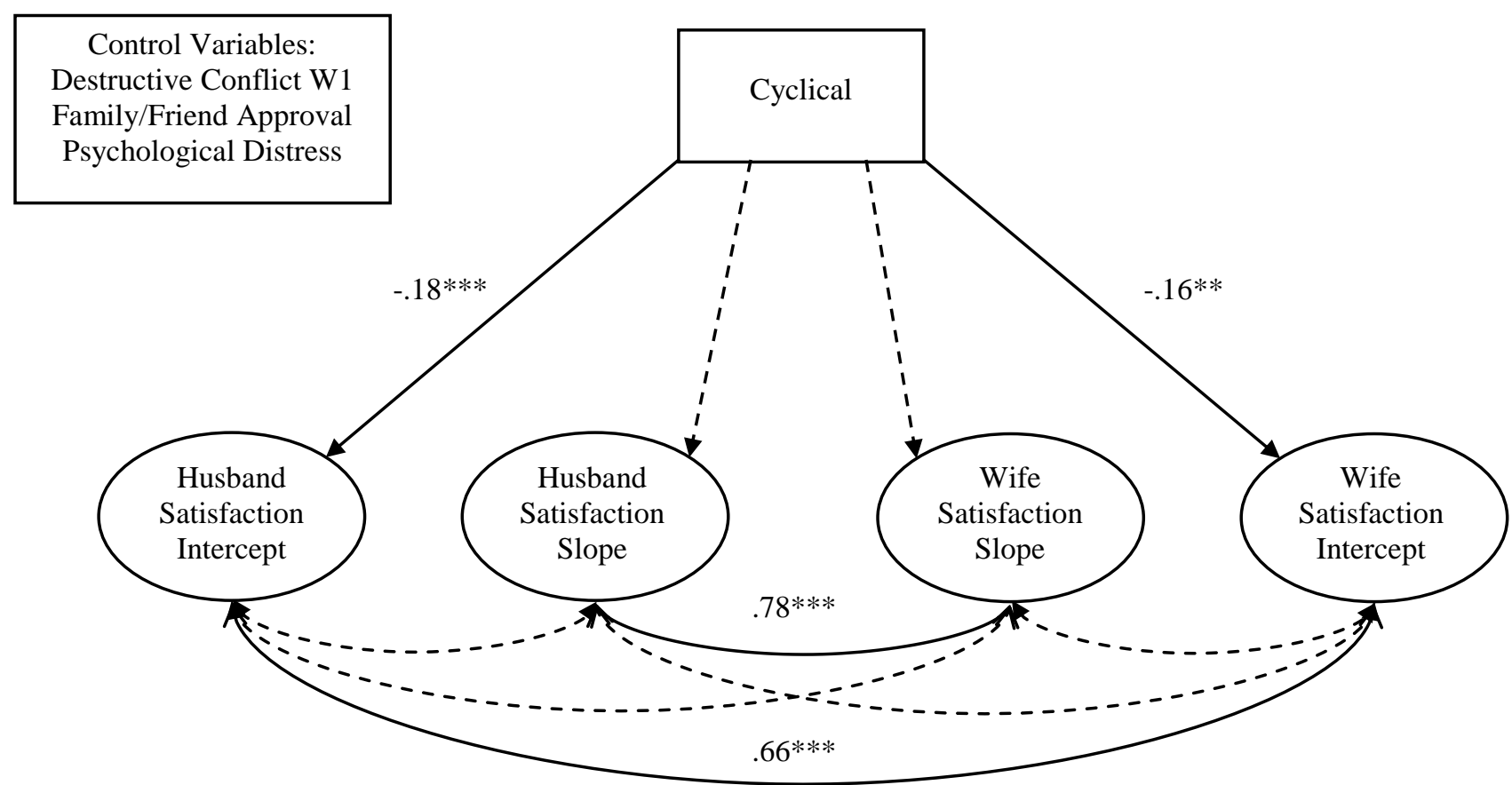

Note: Standardized estimates. For clarity, the paths from the control variables to husbands' and wives' slope and intercept variables are not shown, but were included in the analysis. Model fit indices: $\chi^{2}(28)=69.61, p<.001 ;$ RMSEA $=.05$ (C.I. $\left.=.04, .07\right) ;$ CFI $=.97 ;$ TLI $=.94 ;$ SRMR $=$ .07.

$* p<.05 . * * p<.01 . * * * p<.001$ (two-tailed). 